\title{
Approaching models of nursing from a postmodernist perspective
}

Philip Lister RMN, RNT, RCNT, CertEd(FE) Nurse Tutor, Hereford and Worcestershire College of Nursing arid Midwifery, Nurse Education Centre, County Hospital. Hereford HRI 2ER, England

Accepted for publication 1 August 1990

LISTER P. (1991). Journal of Advanced Nursing 16, 206-212

http://onlinelibrary.wiley.com/doi/10.1111/j.1365-2648.1991.tb01626.x/abstract

This paper explores some questions about the use of models of nursing. These questions make various assumptions about the nature of models of nursing, in general and in particular. Underlying these assumptions are various philosophical positions which are explored through an introduction to postmodernist approaches in philosophical criticism. To illustrate these approaches, a critique of the Roper et al. model is developed, and more general attitudes towards models of nursing are examined. It is suggested that postmodernism offers a challenge to many of the assumptions implicit in models of nursing, and that a greater awareness of these assumptions should lead to nursing care being better informed where such models are in use.

\section{INTRODUCTION}

Should we be looking for the one model of nursing which will shed light on nursing activities in the widest range of settings (Hardy 1978)? Or should we be trying to match particular models of nursing to certain specialities (McKenna 1989)? Should we be choosing the model most appropriate to help an individual client at this moment in time (Wilde 1988)? Or should we be building our own model from selected parts of others (Collister 1988)? Or should we even be developing our own by discussion amongst the members of the team as an ongoing process (Wright 1986)?

The above options have been discussed by various authors to different degrees, from the comparison of several to the presumption of the correctness of one. It is this latter approach which is likely to lead to poorly informed nursing care, when a model of nursing is adopted or imposed without full consideration of the underlying assumptions and values of the model. In this situation, an individual nurse may be unsure of what the model requires and may have his or her own doubts (McKenna 1990). The nursing care actually received by the client may reflect this dissonance 
However, there is pressure on nurses and nursing teams to adopt a model of nursing, and this pressure from educationalists, academics and managers may lead to models being introduced to practice settings in a way that does not involve the staff in exploring these questions and assumptions (Chapman 1990). The introduction of the 'nursing process' has been said to have happened in a similar way, with many nurses yet to be totally convinced of its value (Salisbury 1985).

It is hoped that this paper will provide a strategy for considering these questions, an attitude towards models of nursing. This will allow us to explore the varieties of unstated values and assumptions which lie behind these questions, and to determine our own approach to their answers.

The paper will start by outlining some arguments for and against using single or multiple models of nursing, which will lead to an examination of the philosophical basis of thought about nursing. Following this different philosophical approaches that have developed in contrast to one another, will be outlined leading on to an exposition of the postmodernist perspective in philosophy.

This postmodernist perspective will then be used to develop a critique of one model of nursing in particular and for the consideration of models of nursing in general.

\section{MODELS OF NURSING}

Fawcett (1984) outlines the main arguments for both single and multiple use of models of nursing. He says that most disciplines use several models rather than a single one. This enables them to explore phenomena in a variety of ways'. In nursing it will allow us to explore the nature of 'nursing more fully. It will also avoid the danger of nursing as a profession stagnating, but will allow nursing to evolve. It also gives the individual practitioner more choice to exercise judgement.

However, a single conceptual unified model of nursing would lend 'stability to the profession. It would help in transferring information between educational programmes and clinical settings, and between varieties of clinical settings and agencies.

\section{Limitations}

But there are possible limitations. What if the model was not actually appropriate for all the clinical and community settings, or for all problems dealt with by nurses? Would this move the problems out of the remit of nurses and into the hands of others? Or what if the model was not appropriate for all the cultural groups in the populace?

At present, it could be argued that none of the existing models of nursing could avoid the above limitations. We are still at the "preparadigmatic" stage of theory development, where there are differing and competing models to explain the same phenomena (Hardy 
1978). As nursing evolves, Hardy argues, we should expect a "metaparadigm' to emerge. This would be an all-embracing model which would encompass the differences between models of nursing as we presently understand them.

The attitude which leads us to expect a metaparadigm to emerge will be questioned below. The same attitude would lead us to expect to find that certain models are more appropriate to certain client groups or settings. It is, the author thinks, a temptation for nurse managers in both service and education to choose a model on which to base nursing care and nurse education without fully exploring the implications of that choice.

Therefore, we need to examine this attitude closely to determine its origin and its alternatives. Numerous accounts exist which point to how the move from nursing task orientation to nursing process-orientation' has become a well-meaning exercise in bureaucracy, as much as a revolution in nursing (Salisbury 1985). It is the unspoken assumptions and values of nurses which need to be looked at from a philosophical perspective. Without this there is a danger that models of nursing will be seen as further bureaucratic impositions (Loughlin 1988).

\section{PHILOSOPHY AND NURSING}

The relevance of philosophy to nursing has been discussed in several places (Griffen 1980, Tadd \& Chadwick 1989, Woods \& Edwards 1989). Gortner (1983) looks at the historical development of approaches to theory and research in nursing. He notes how nursing theorists who have trained to doctoral level in other fields often bring with them methods which have served them well there. These methods usually have an underlying but unspoken philosophical leaning towards logical positivism.

Silva \& Rothbart (1984) discuss two competing schools of philosophy, those of logical positivism and of historicism. They propose that until 1969 logical positivism under. pinned almost all nursing theory. Then in the early 1970s, whilst logical positivist theories in nursing were still pervasive, philosophers of science were moving away from this position towards historicism. The trends they identify since then have been towards both making logical positivism more explicit, and developing nursing theories reflecting a move to historicism.

Rodgers (1989) also points out the underlying logical positivism in approaches to concept analysis in nursing. She states that:

... such tenets have fallen into disrepute among contemporary philosophers with the demise of positivism and its emphasis on the value arid context-free nature of knowledge and a focus on reduction. Yet such a foundation persists in the approach to analysis currently employed in nursing 
It is to these contemporary philosophical approaches that we now turn.

\section{FROM LOGICAL POSITIVISM TO POSTMODERNISM}

Positivism rejects metaphysical statements: that is, statements unsupported by sensory evidence or logical deduction. Concepts such as 'mind and 'soul' have no place in this approach. Logical positivism would aim to be able to describe them only in terms of what is observable and testable. Traditional behavioural psychology is an embodiment of this. Nursing models such as that proposed by Johnson (1980) are based on this perspective. Reason and logic are valued, as is the ability to reduce a complex phenomenon to manageable (by reason and logic) elements.

The type of philosophy known as metaphysical is in contrast to this reductionist approach. Humanistic psychology and nursing models such as Rogers' (1970) model are influenced by this way of thinking. The basis of the metaphysical philosophies is the acceptance of a different order of reality beyond day-to-day experience. This can be taken to refer to a 'spiritual dimension, but it can also be argued that the pursuit of 'truth through science is also a metaphysical notion.

An influential criticism of both positivist and metaphysical positions was begun by the anthropologist Levi-Strauss (1979). He postulated that all philosophical enquiry is essentially a matter of language.

\section{Language}

Language in this view does not refer to anything other than itself. There is no other presence 'out there, beyond language. That is, the way we experience the world is determined by language, or at least by some underlying structure which gives shape to both language and our experience of the world (Solomon 1988). As this idea of the significance of an underlying structure is central, it is referred to as 'structuralist' philosophy. Structuralism replaces a concern for 'truth' or 'meaning' with a concern for underlying structures, with an exploration of how 'meaning' is constructed. Subjective experience is secondary in this context.

No present model of nursing seems to reflect this approach, though Jungian psychoanalysis and techniques such as neuro-linguistic programming seem to have been influenced by this outlook (Lewis \& Pucelik 1982, Jung 1972).

However, this notion of an underlying and ordering structure can be recognized to correspond with the very idea of something 'out there', separate from direct experience. There is a continued separation of the idea of the 'self (confined within the structure and experience of language) and the metaphysical 'not-self' (the universal structure of experience). This continuing but unacknowledged metaphysical position was the source of a new criticism, especially in the figure of Jaques Derrida (Derrida 1967, Culler 1979).

This 'post-structuralist' philosophy tries to offer comment and criticism without falling into the 
metaphysical trap and without recourse to the reductionism of logical positivism. It is in a sense a critical juggling act using language to comment on the nature of language, ideas to comment on ideas, without either limiting the discourse to easily controlled phenomena (as in logical positivism) or expanding the discourse to limit our responsibility (as in metaphysics). Though the terms 'post-structuralism' and "postmodernism' are under constant debate, the latter term is being used in this paper to refer to the philosophical approach exemplified by Derrida.

As ideas about nursing are discussed increasingly and developed in an academic as well as practical context, it is impossible in this discussion to avoid reflecting the prevailing cultural philosophies. Postmodernism above all provides a strategy for identifying and responding to the implicit values and beliefs within a philosophy.

\section{THE RELEVANCE OF POSTMODERNISM}

From the above comments about the lineage of postmodernism, it should be clear that there is no all-embracing postmodernist philosophical position. Derrida describes his work as 'a sort of strategic device' rather than a system (Derrida 1983). This strategic device has become known as 'deconstruction' (although Derrida has expressed dislike for the term, as the term itself becomes, by naming, part of the structure which is being challenged by the process). Deconstruction is not a procedure or technique. It cannot be reduced to a series of stages. Pheby (1988) describes it as "an ongoing work, not a position or a standpoint - but a praxis, an activity, an "exercise in disruption' ". Norris \& Benjamin (1988) state that

To "deconstruct' a text is to draw out conflicting logics of sense and implication, with the object of showing that the text never exactly means what it says or says what it means.

Essentially, it seems to be a process of analysing the form and content of a communication and following through discrepancies to explore underlying logical and attitudinal inconsistencies. The form and content are regarded as inter. dependent. Dickoff \& James (1986) use a similar approach in many of their analyses of theories of nursing. At first sight, this may seem to be a limited academic exercise, but if becomes very relevant when the 'communication being exposed to the process of deconstruction is more than a conventional written text.

For example, the communication could be a cultural one: that high-technology Western culture is preferable to other cultural systems. Pheby (1988) has argued that cultural imperialism, Third World poverty and global pollution can all be traced back to a particular Western way of thinking which alienates the concept of "self from the other'. This was given powerful support by the endorsement of positivism by technological growth, the power to make such huge transformations in society by industry.

\section{Dominance of Western models}

In this context, it is interesting to see how Western models of health, illness and health care have come to dominate Third World Countries. Whilst this has many positive aspects, there is 
an element of unrealistically high regard given to some aspects of Western technological medicine and training. It is reported (Roper \& Logan 1985) that one particular model of nursing explored below has begun to interest a number of developing countries'. Perhaps we need to be wary of the effect that the adoption of such models of nursing may have in these settings.

Because of the threatening possibilities of the positivist position, postmodernism offers a valuable approach to make us sensitive to these underlying attitudes. The positivist attitude carries with it many assumptions about power and relationships. It will be valuable to examine the assumptions underlying models of nursing, and to see what implications these have for the power relationship between nurses and those 'nursed'.

To this end, the author wishes to show how a postmodernist perspective can be used to develop a critique of a particular model of nursing as well as of the attitudes and expectations surrounding the concept of "models of nursing in general.

\section{CRITIQUE OF A PARTICULAR MODEL}

The Roper model for nursing (Roper et al. 1980, 1981, 1983) has been widely adopted in the UK, especially in the field of general nursing and nurse education for RGN courses It offers a framework comprising 12 'activities of living, each with a continuum of dependence to independence. It is derived from Virginia Henderson's model (Henderson 1966) and has been in development from the early 1970s. This model has been chosen because it is believed that a critique will go towards explaining the widespread adoption and will also bring out underlying questions which need to be addressed.

Roper et al. are keen to stress that they are offering a practical model: that is, one that can be readily used. To this end, their publications often include full-size blank documentation for use in the nursing notes. They differentiate between their model and more "academic models, being careful to name their model one 'for' nursing rather than a model 'of' nursing.

The aim here is to show how the application of a strategy of deconstruction can bring out aspects of the model which otherwise remain implicit, exerting an influence under the surface of the texts. This author particularly wants to explore the two main claims which the authors make for this model. These seem to be:

1. that the model describes the very 'elements of nursing' in such a way as to make it applicable to any setting or situation where nursing occurs,

2. that the model has a particular strength in its ability to link theory to practice.

\section{The elements of nursing}

As a strategy, deconstruction has been criticized for the attention it sometimes pays to the peripheries of a text whilst almost ignoring the writer's main arguments (Norris 1987). This is to miss the point of the postmodernist position, that what the writer writes in conveying his or her ideas also conveys implicit assumptions and unacknowledged attitudes that sometimes run counter to the stated position. 
Beginning on the periphery of the texts which convey the ideas of Roper et al, it can be seen that one particular quote they use assumes significance.

It has been said and written scores of times that every woman makes a good nurse. I believe on the contrary that the very elements of nursing are all but unknown. (Nightingale 1859)

This passage is quoted several times in various places, three times in the first textbook to describe the model whose very title is taken from the quote itself (Roper et al. 1980, 1986).

Yet what are the implications of this quote occurring with such frequency and indeed lending itself to the title of the book The Elements of Nursing (Roper et al. 1980) almost as a subtitle for the model described within?

The first implication is the setting of this model in a historical context, a context which juxtaposes the proposed model with the words of a traditionally respected figure in the international (and especially British) nursing scene. By implication, the model is given a hint of authority. This appeal to authority is very firmly in the tradition of a hierarchy of influence and power which is implicit in a positivist outlook. Positivism views the development of knowledge as linear and progressive, and the authors of the model appeal to this assumption by presenting their ideas in this historical context.

Second, the implication is that the model proposed actually makes known the 'elements of nursing' which Nightingale was unable to expose. There are several aspects to this implication.

1. that the model is a further development, a progression, from Nightingale's ideas. This reflects an attitude based on a positivist premise: that progress is made by a constant refinement of earlier attempts at the truth until the 'truth' is found.

2. that the model describes the 'elements of nursing' applicable in any nursing context. That is, it suggests it has the status of a metaparadigm. It will be argued below that the idea of a 'metaparadigm' can be linked with the metaphysical and positivist positions.

Now, no such grand claims of metaparadigm status or authority are made in the writings of Roper et al. In fact, they use language very carefully in places to show the boundaries of their endeavour. As noted above, they are particularly careful to describe the model they offer as a model for nursing, suggesting a model for activity rather than description. However, the implication from the repetition of this quote runs counter to their intentions, as a deconstructive reading can suggest.

\section{Theory and practice}

This brings us to the second claim, that the model is not intended primarily as a theoretical construction, but as one to inform practice. To this end Roper ei al. have edited a series of commissioned articles to illustrate how the model can be used in a variety of settings (Roper et 
al. 1983). This author has discussed elsewhere that it is evident from at least one of these reports that the framework of Roper's model could be used to describe and record nursing care, which is in fact being planned according to the medical model (Lister 1987).

In Roper's early paper which formed a basis of this model (Roper 1976), she clearly included provision for the nurse carrying out activities which are medically prescribed. This provision is retained in a less explicit form in the later developments of the model (Roper et al.1980,1981).

The medical model has been criticized by many authors for its embodiment of positivist and patriarchal values (Webb 1986, Collister 1988). It is not being suggested here that Roper and her colleagues subscribe to the points on which the medical model is criticized, but this author is pointing out the implicit endorsement, in the Roper et al. model, of the nurse's role in the medical model. This role may on occasions require the nurse to withhold information from the patient, offer unwise reassurance, and ensure Compliance with medical directives among other things. These are generally considered to be poor nursing practices, from a professional point of view, but can traditionally be expected of nurses by their medical colleagues. This expectation is based on implicitly positivist values which can be held by both doctors and nurses. So the adoption of this model does not necessarily empower nurses to act with their own authority in the patient's interests.

The author would even suggest that the widespread adoption of this model, particularly in the UK, would suggest that it is offering little in the way of changing nursing practice. It may be that though the authors make a careful claim for it to be a model 'for' rather than "of nursing, under the pressure to adopt a model as discussed earlier in this paper many nurses are grateful to be seen to be adopting it as a model of nursing. Indeed, the authors' careful semantics are often ignored when included in discussion about nursing models (Aggleton \& Chalmers 1985).

We have in the Roper et al. model a generally accepted (in the UK) 'model of nursing' which the authors are careful not to claim as such. The status of this model as a model of nursing, in this deconstructive reading, is questioned. Indeed, in practice it seems to be offering an assessment and evaluation format which many will find useful but which allows nurses to maintain their practice and the status quo against many pressures within and outside the profession. Its adoption will not necessarily (and does not in fact) give to nurses a new perspective on nursing activity, or challenge entrenched viewpoints.

In making these points, the author is aware that Roper et al. would not necessarily subscribe to them. However, what is intended is to show that the text can be 'deconstructed', can be shaken and loosened so that what Roper et al. mean to say and what the text actually says it means can be seen not always to correspond.

\section{MODELS OF NURSING IN GENERAL}

Having illustrated how the postmodernist strategy of deconstruction can be used to develop a critique of a particular model of nursing, this discussion will now turn to the way in which such models are discussed and considered. It is in the collective consideration of models of nursing that a postmodernist perspective is perhaps most useful.

From this position, it can be seen that the search for a generally applicable model of nursing is 
based on positivist presuppositions: that experiment and refinement will eventually find the best model. Even the search for a single model for use in a unit, and implemented from above in the hierarchical structure, presupposes an acceptance or compliance with positivist values.

Hardy's expectation of the emergence of a 'metaparadigm' of nursing (1978) is an expression of positivist optimism. This metaparadigm refers to a usable system rather than to a metaphysical presence. But it does suggest the existence of an underlying "truth about nursing which is certainly influenced by metaphysical beliefs.

McKenna (1989) describes a piece of research which attempts to identify which one of 19 given models of nursing a group of 98 ward managers finds most appropriate for long-stay psychiatric wards. The research described shows an unstated acceptance of the positivist approach. It limits itself to what can be measured and uses the principles of reductionism to simplify each of the 19 models to four short statements. From this basis, one model is recommended as the most appropriate, and this is contrasted with the fact that another model is being endorsed more widely, presumably without the benefit of supporting research (such as his own)

\section{Positivist values}

Positivist values have been discussed by Collister (1988), who distinguishes between reductionist and non-reductionist models of nursing. He suggests that reductionist models would tend to assess the patient's progress in a mechanistic way, against criteria implicit in the model and that non-reductionist models would be more individualistic. But he goes on to qualify this distinction as simplistic and perhaps misleading. This awareness of the falseness set up by a method of inquiry based on reductionism (the distinction between reductionist and nonreductionist models being a symptom of a reductionist premise itself) is typical of the postmodernist process.

Postmodernism also has links with feminist critiques of male-value dominated science and technological change, where positivism is seen to affect the power structure between the sexes (Tinkle \& Beaton 1983, Hagell 1989). Stanley \& Wise (1981) are critical of how both men and women adopt positivist attitudes in a patriarchal society. This can be seen, of course, in nursing as much as anywhere.

\section{CONCLUSION}

What postmodernism offers us is an argument to consider in defence of an eclectic approach to models of nursing. By eclectic, in this context, is meant an approach which draws on various models rather than one. But this eclecticism needs to be an ongoing process of challenge and exploration, rather than an amalgamation (Wright 1980). This Will run counter to the values of many nurses, and may only occur at some future time when a radical shift in thinking, a 'Kuhn paradigm', appears (Kuhn 1970, Barnes 1982).

A new paradigm is becoming apparent in nursing, mainly through the influence of ideas and attitudes from humanistic psychology, feminism and non-Western philosophies. Concepts Such as holistic care and the empowerment of people to influence their own health status are two examples of a non-positivist paradigm. 
But this is in constant opposition to more positivist and metaphysical philosophies in society, including the values inherent in a free market economic context of health care provision.

\section{Continually self-questioning}

Perhaps we need to be able to sidestep this opposition of values and be able to attain a perspective which is mindful of the danger of oversimplifying the situation and which is continually self-questioning. That this is not an easy task, that it is paradoxical but necessary, must be recognized:

The search for truth is not to be halted - for we do not know how this can be done. Our beliefs are shaken but they are not to be replaced with others. No theory is safe from the Derridean onslaught but equally no theory is proclaimed. Yet theories of one form or another cannot be avoided. (Lawson 1985)

Perhaps a greater engagement with postmodernist philosophy will help lead us away from our usual oppositional and exploitative ways of thinking and acting and into areas where we will be better able to empower patients and clients to become equal collaborators in health care, and able to defend our position against arguments based on metaphysical and positivist ideas.

\section{Acknowledgements}

I would like to thank Delia Pheby and Dr Keith Pheby of Strathclyde University for initial encouragement and for commenting on an earlier draft of this paper. 


\section{References}

Aggleton P. \& Chalmers H. (1985) Roper's activities of living model. Nursing Times 81(7), 59-6I

Barnes B. (1982) T.S. Kuhn and Social Science, Macmillan, London.

Chapman C. (1990) A critical perspective. In Models for Nursing. 2 (Kershaw B. \& Salvage J. eds), J. Wiley, Chichester.

Collister B. (1988) Psychiatric Nursing: Person to Person. Edward Arnold, Sevenoaks.

Culler J. (1979) Jacques Derrida. In Structuralism and Since; from Levi-Strauss to Derrida

(Sturrock J. ed) Oxford University Press, London

Derrida J. (1967.) Of Grammatology (transl. Spivak G\}, Johns Hopkins University Press Baltimore

Derrida J. (1983) The time of a thesis: punctuations in Philosophy in France Today (Montefiore A. ed.), Cambridge University Press, Cambridge

Dickoff J. \& James P. (1986) Techniques Dickoff/James employed in their critique of Walker. In Perspectives on Nursing Theory (Nicoll L.H. ed.), Scott, Foresman, London, pp. 57-58.

Fawcett). (1984) Analysis and Evaluation of Conceptual Models of Nursing. F.A. Davies, Philadelphia.

Gortner S.R. (1983) The history and philosophy of nursing Science and research. Advances in Nursing Science 5(2), 1-8.

Griffen A.P. (1980) Philosophy and nursing. Journal of Advanced Nursing 5, 261-272.

Hagell E.J. (1989) Nursing knowledge: a woman's knowledge. A Sociological perspective Journal of Advanced Nursing 14, 226-233.

Hardy M.E. (1978) Perspectives on nursing theory. Advances in Nursing Science 1(j), 37-48.

Henderson V. (1966) The Nature of Nursing. MacMillan, New York.

Johnson D. (1980) The behavioural system model for nursing In Conceptual Models for Nursing Practice (Reihl J.P. \& Roy C, eds), Appleton-Century-Crofts, Norwalk, Connecticut.

Jung C.J. (1972) Four Archetypes. Routledge and Kegan Paul, London.

Kuhn T.S. (1970) The Structure of Scientific Revolutions. University of Chicago Press, Chicago,

Lawson H. (1985) Reflexivity: The Post-Modern Predicament. Hutchinson, London. (1979)

Levi-Strauss C (1979) Structural Anthropology. Harmondsworth.

Lewis B.A. \& Pucelik R.F. (1982) Magic Demystified; A Pragmatic Guide to Communication and Change. Metamorphous Press, Lake Oswego, Oregon

Lister P.E. (J987). A misunderstood model. Nursing Times 83 (41), 40-42

Loughlin M. (1988) Modelled, muddled and befuddled. Nursing Times 84(5), 30-31

McKenna H.P. (1989) The selection by ward managers of an appropriate nursing model for long-stay psychiatric care. Journal of Advanced Nursing 14, 762-775.

McKenna H.P. (1990). Which Model? Nursing Times (25), 50-52. 
Nightingale F. (1859, reprinted 1974) Notes on Nursing. Blackie, London.

Norris C. (1987) Derrida. Fontana, London,

Norris C. \& Benjamin K. (1988) What Is Deconstruction? Academy Editions, London.

Pheby K.C. (1988). Interventions. Displacing the Metaphysical Subject. Maisonneuve Press, Washington.

Rodgers B.L. (1989) Concepts, analysis and the development of nursing knowledge: the evolutionary cycle. Journal of Advanced Nursing 14, 330-33.5

Rogers M.E. (1970) An Introduction to a Theoretical Basis of Nursing. F.A. Davies, Philadelphia.

Roper N. (1976) A model for nursing and nursology. Journal of Advanced Nursing 1,217-219.

Roper N. \& Logan W. (1985) The Roper/Logan/Tierney model. Senior Nurse 3 (2), 20-26.

Roper N., Logan W. \& Tierney A. (1980) The Elements of Nursing. Churchill Livingstone, Edinburgh,

Roper N., Logan W. \& Tierney A. (1981) Learning to Use the Process of Nursing. Churchill Livingstone, Edinburgh

Roper N, Logan W. \& Tierney A. (1983) Using a Model for Nursing. Churchill Livingstone, Edinburgh.

Roper N. Logan W. \& Tierney A. (1986) Nursing models: a process of construction and refinement. In Models for Nursing (Kershaw B. \& Salvage J. eds), J. Wiley, Chichester.

Salisbury D. (1985) Don't waste the process. Nursing Times 81(10), 42.

Silva M.C. \& Rothbart D. (1984) An analysis of changing trends in philosophies of science on nursing theory development and testing. Advances in Nursing Science 6(2), I-13.

Solomon R.C. (1988) Continental Philosophy Since 1750. The Rise and Fall of The Self, Oxford University Press, Oxford.

Stanley L. \& Wise S. (1981) Breaking Out. Feminist Consciousness and Feminist Research. Routledge and Kegan Paul, London.

Tadd W. \& Chadwick R. (1989) Philosophical analysis and its value to the nurse teacher. Nurse Education Today 9, 155-160

Tinkle M.B. \& Beaton J.L. (1983) Toward a new view of science; implications for nursing research Advances in Nursing Science 5(2), I-8.

Webb C. (ed.) (1986). Women's Health; Midwifery and Gynaecological Nursing. Hodder and Stoughton, London,

Wilde V. (1988) Care plan for an obsessional person using a cognitive-behavioural model. In Psychiatric Nursing: Person to Person (Collister B. ed.), Edward Arnold, Sevenoaks.

Woods S. \& Edwards S. (1989) Philosophy and health. Journal of Advanced Nursing 14, 661664.

Wright S.G. (1986) Building and Using a Model of Nursing. Edward Arnold, Sevenoaks. 